\title{
Sub-acute anterior myocardial infarction due to the discontinuation of warfarin in a patient with aortic valve prosthesis: what is the best treatment
}

Acute myocardial infarction (MI) is a common entity in patients due to the atherosclerotic plaque rupture or coronary embolism. We present a patient who had a mechanical aortic valve and was admitted to the hospital for a sub-acute anterior ST elevation myocardial infarction due to the discontinuation of warfarin. In case of persistent thrombus formation despite aggressive antithrombotic and anticoagulant therapy, thrombus aspiration, angioplasty and stenting should be preferred rather than conservative approach.

Submitted: 23 May 2015; Accepted: 30 June 2016; Published online: 30 June 2016

Acute myocardial infarction (MI) is a common entity in patients due to the atherosclerotic plaque rupture. But there are other susp10cious etiologic reasons that lead to coronary embolism such as intra-cardiac prosthesis, infective endocarditis, mural thrombus or a cardiac tumor [1-7]. Even if the patient did not use warfarin, the real reason for acute myocardial infarction whether embolism or atherosclerotic plaque ruptures should be revealed in order to decide optimal treatment option. Intravascular ultrasonography and optical coherence computed tomography are very useful to diagnosis so which treatment is the best; thrombolysis, angioplasty or stenting. Previous cases of coronary emboli in association with prosthetic mechanical valves have been reported previously but the treatment is controversial [8-16]. We present a patient who had a mechanical aortic valve and was admitted to the hospital for a sub-acute anterior ST elevation myocardial infarction due to the discontinuation of warfarin.

\section{Case}

A 58-year-old male presented with severe retrosternal chest and back pain radiates to his left arm for 20 hours was admitted to our coronary care unit. His symptoms were resolved on admission. He had previous mechanical aortic valve implantation nine years earlier because of a rheumatic aortic valve. The patient did not have a history of traditional cardiovascular risk factors except smoking (1 pack a day) and hypertension. No other comorbidities are present. His familial medical history is otherwise unremarkable. Pulse rate was 68/bpm, regular, arterial blood pressure was $110 / 70 \mathrm{mmHg}$, lungs were clear breath rate was $18 / \mathrm{pm}$, no murmur on physical examination. Systolic ejection murmur grade $2 / 6$ on the second right parasternal space and a mechanical valve click was heard with the cardiac auscultation. The electrocardiography (ECG) revealed ST-segment elevation in the precordial leads consistent with sub-acute anterior myocardial infarction (MI); ST
Antonio L Aguilar-Shea*

Centro de Salud Puerta de Madrid, Spain *Author for correspondence: Tel.: +34918806699 antonio.aguilar@salud.madrid.org 
segment elevation in V1-6, T inversions and pathological $\mathrm{Q}$ waves on admission (Figure 1). There was significant elevation of the cardiac markers (troponin $\mathrm{T}$ level of $8022 \mathrm{ng} / \mathrm{ml}$ and creatinine kinase-MB level of 340 U/L). The patient's INR level was 1.34 reflecting an unprotected and prothrombotic state. Physical findings were not remarkable. The patient was diagnosed to have a sub-acute anterior ST-elevation myocardial infarction (STEMI). Left ventricular ejection fraction(LVEF) was $30 \%$ and severe akinesia of the anterior and apical wall of the left ventricle was detected on transthoracic echocardiography so we started the dual anti-platelet therapy (aspirin $300 \mathrm{mg}+180 \mathrm{mg}$ ticagrelor as for loading dosage), and unfractionated heparin infusion. After that, the patient was transferred to the catheter laboratory and coronary angiography (CAG) showed total occlusion of the proximal part of the left anterior descending artery (LAD) (Figure 2). There were no significant stenosis on the right coronary artery and circumflex artery. We advanced a 0.014 inch floppy guide wire and passed through the lesion, we attempted to aspirate the thrombus three times by using intracoronary catheter aspiration was but was not successful. The occlusion was inflated with $1.5 \times 15$ $\mathrm{mm}$ and $2.5 \times 15 \mathrm{~mm}$ balloons (Figure 3 ) but they were also unsuccessful due to the severe residue coronary thrombus (Figures 4-7). A drug eluting stent $(3.0 \times 15$ $\mathrm{mm}$ ) was inserted and TIMI flow was so good but distal embolism developed, which completely not obstructed the lumen (Figure 8). The patient was transferred to the coronary care unit and intravenous glycoprotein IIbIIIa inhibitor (abciximab) plus heparin were also started for 24 hours. Control CAG showed the flow was good but there was no thrombus formation in the LAD. The ECG was improved. The patient was discharged 7 days later on acetylsalicylic acid, and beta- blockers, and angiotensin-converting enzyme inhibitor therapy under maintenance of warfarin (with an INR value of 3-3.5).

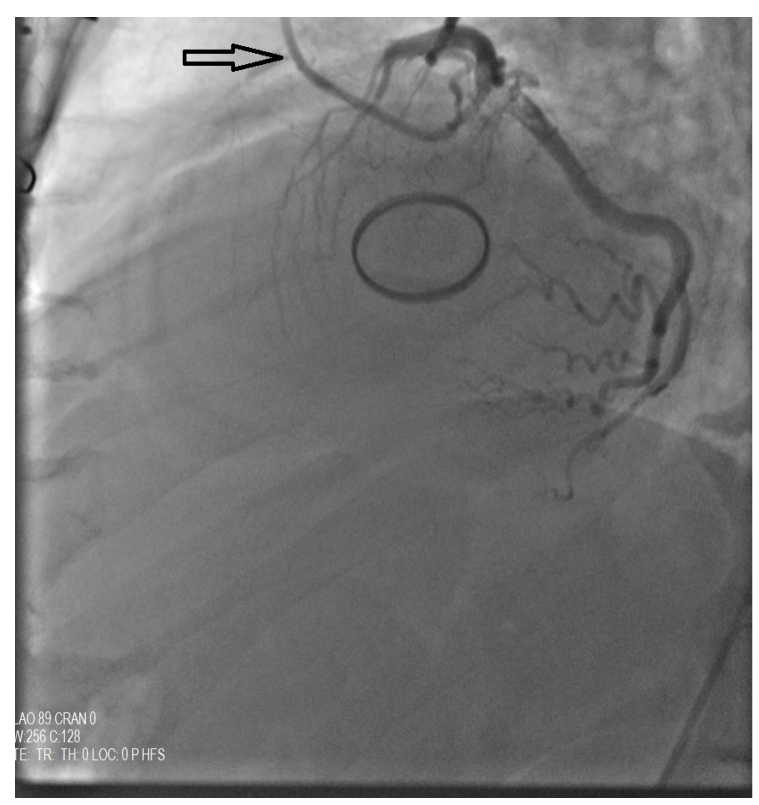

Figure 2: The angiographic images of the patient with total occlusion of the LAD.

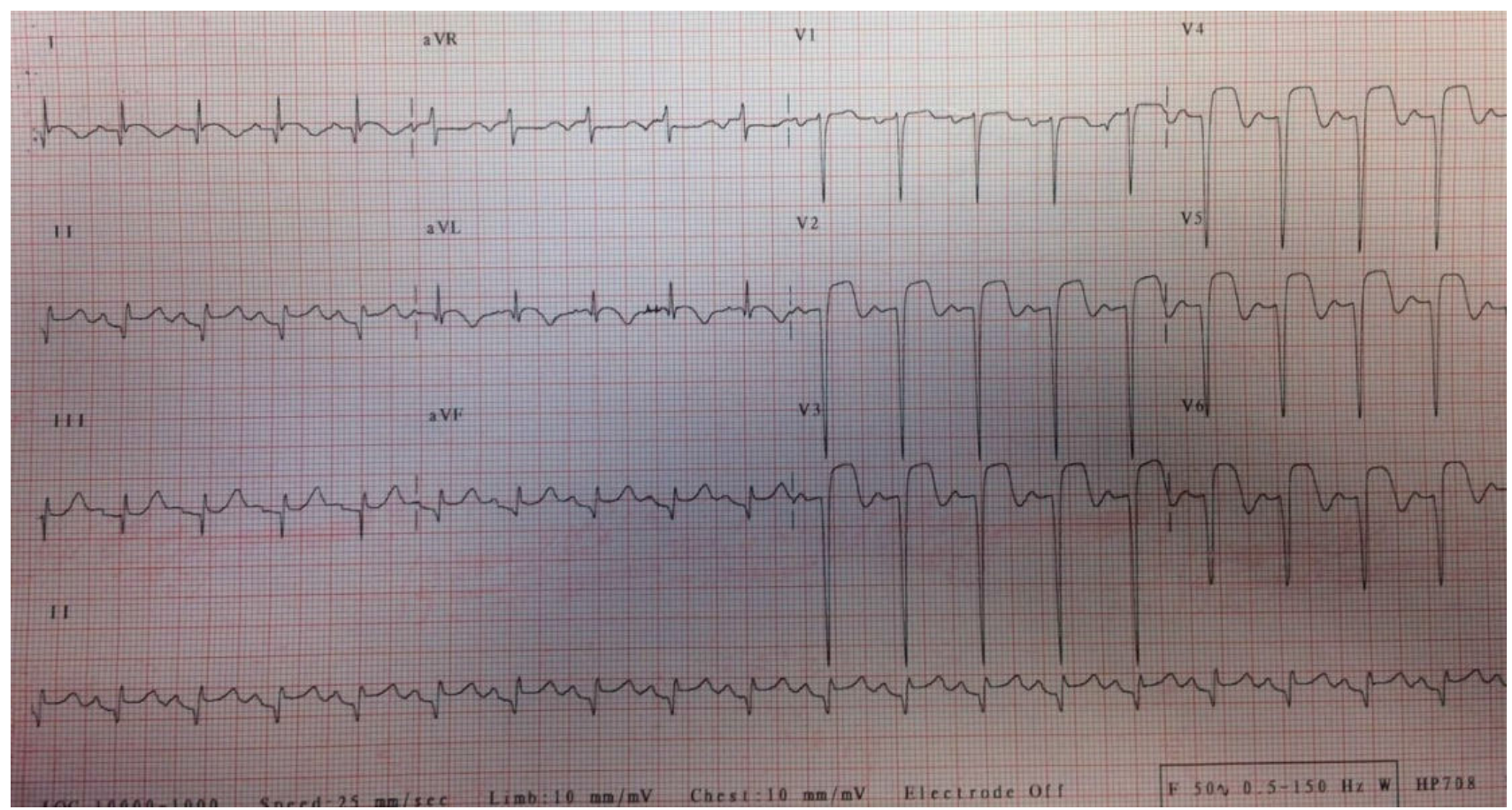

Figure 1: The ECG during admission. 


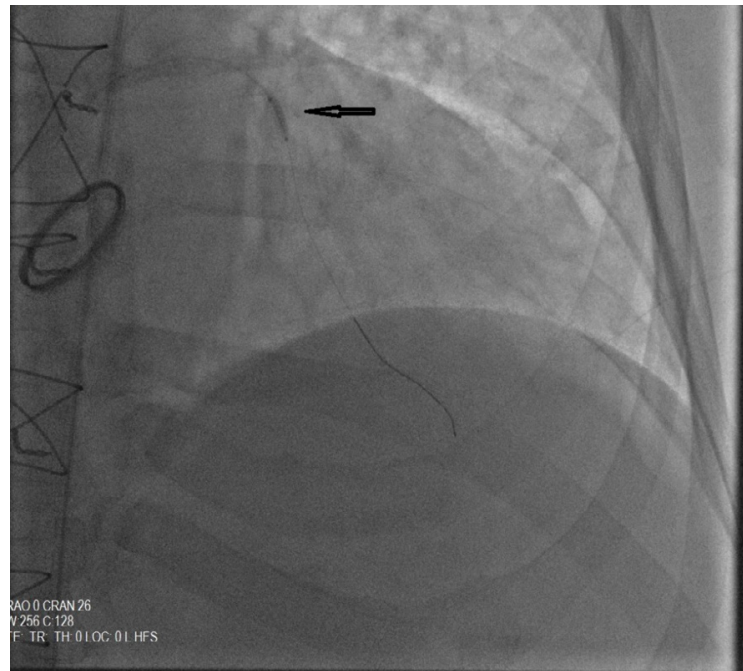

Figure 3: The angiographic images of the patient during balloon inflation.

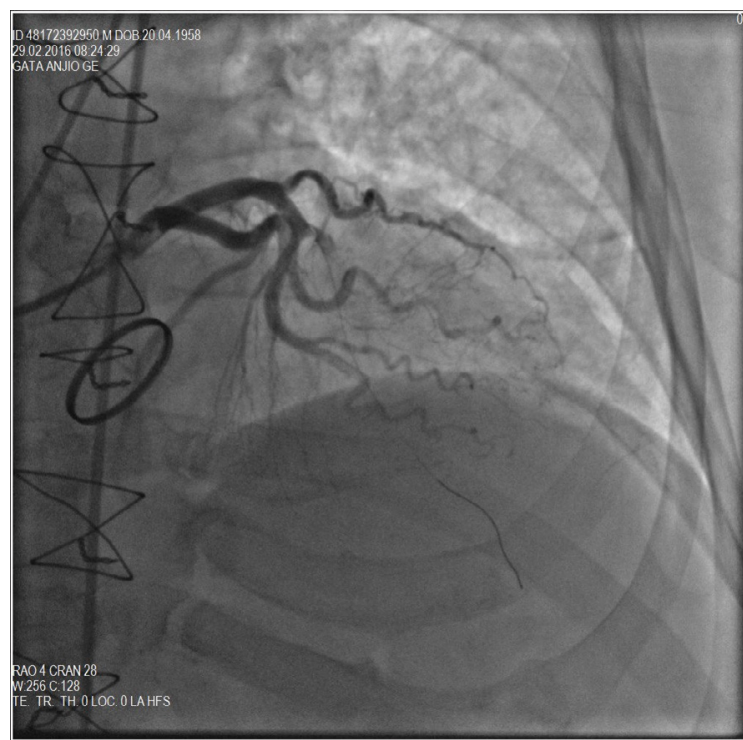

Figure 4: The angiographic images of the patient after first balloon inflation.

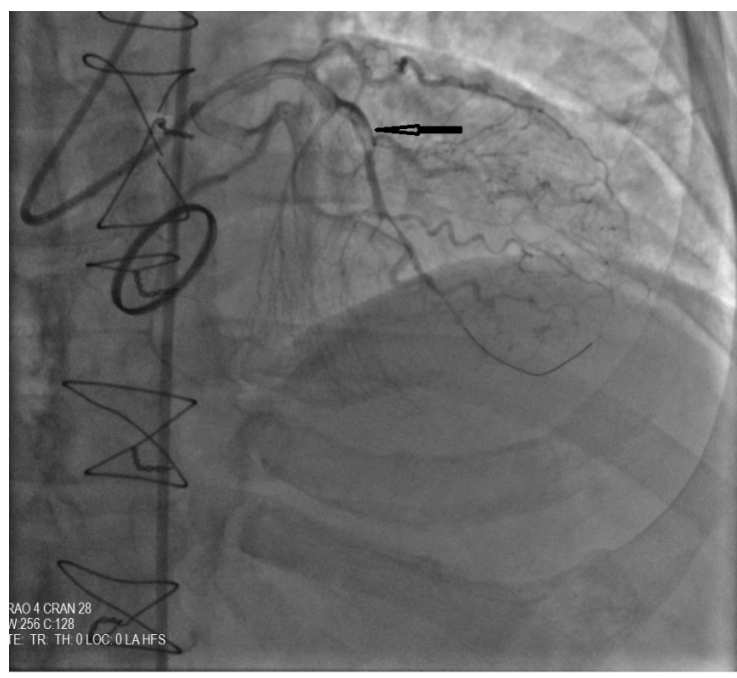

Figure 5: The angiographic images of the patient after second balloon inflation with cranial projection.

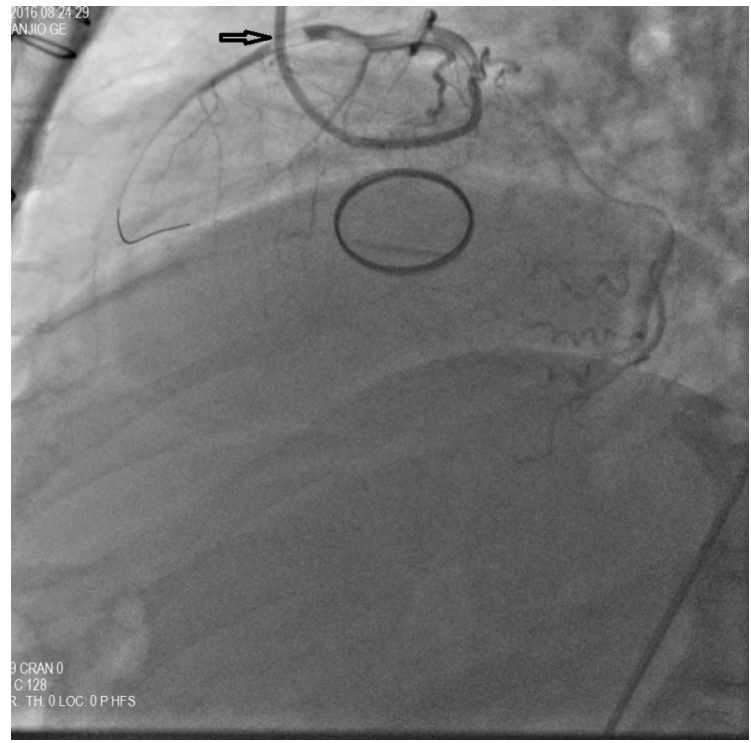

Figure 6: The angiographic images of the patient after second balloon inflation and residue thrombus with cranial projection. 


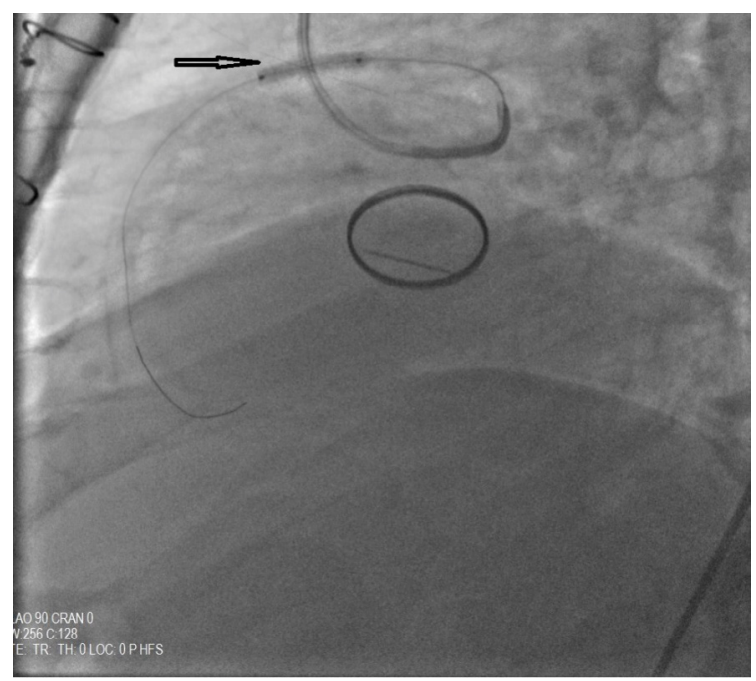

Figure 7: The angiographic images of the patient after second balloon inflation with lateral projection.

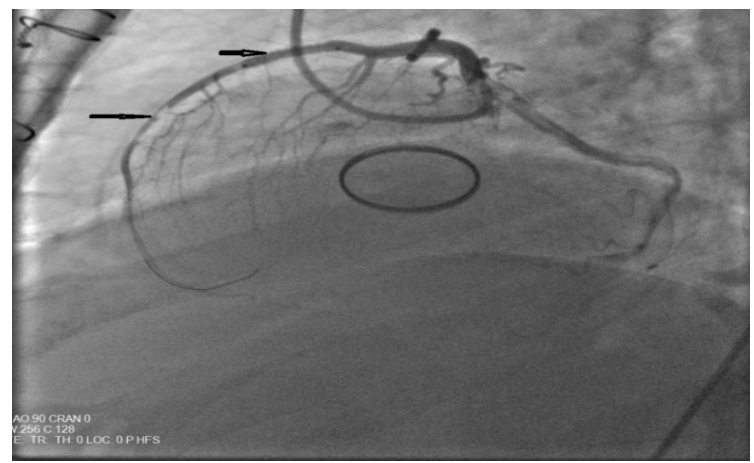

Figure 8: The angiographic images of the patient during stent implantation.

\section{Discussion}

There are many solutions for treatment of coronary embolism. One of them is thrombus aspiration but it may not be enough to track thrombus from coronary vasculature despite several trials with aspiration catheter. The other one is only percutaneous coronary angioplasty without stenting but it may not also obtain optimal angiographic result and TIMI flow. Another choice is stenting in case of all failed interventions. High dosage anti aggregant and anticoagulant therapy are also possible solutions. In case of high thrombus burden causes total occlusion of the coronary vessels, aggressive antithrombotic treatment is feasible in case of low bleeding risk as in our case. So, in case of persistent thrombus formation despite aggressive antithrombotic and anticoagulant therapy, thrombus aspiration, angioplasty and stenting should be preferred rather than conservative approach. A prosthetic mechanical valve requires the use of long-term conventional anticoagulation therapy with warfarin and it is important for the doctors to be lack of awareness of medication of patient who carries significant thromboembolic risk. The choice of treatment should be based on individual decisions and should be set depending on the clinical and comorbid condition of the patient.

\section{Executive summary}

- We present a patient who had a mechanical aortic valve and was admitted to the hospital for a sub-acute anterior ST elevation myocardial infarction due to the discontinuation of warfarin.

- In case of persistent thrombus formation despite aggressive antithrombotic and anticoagulant therapy, thrombus aspiration, angioplasty and stenting should be preferred rather than conservative approach.

\section{References}

1. Patel M, Bhangoo M, Prasad A. Successful percutaneous treatment of suspected embolic left main thrombosis in a patient with a mechanical aortic valve. J. Invasive. Cardiol. 23, 263-266 (2011).

2. Eguchi K, Ohtaki E, Misu K, et al. Acute myocardial infarction caused by embolism of thrombus in the right coronary sinus of Valsalva: a case report and review of the literature. J. Am. Soc. Echocardiogr. 17, 173-177 (2004).

3. Kamishirado H, Yamanaka T, Morooka S, et al. A case of coronary artery embolism associated with combined valvular heart disease. Kokyu. To. Junkan. 41, 81-84 (1993).

4. Härle T, Reimers J, Hertting K, Kuck KH. Successful trapping of an organized thrombus in a coronary artery aneurysm in myocardial infarction: case report and literature review. Cardiovasc. Revasc. Med. 9, 52-55 (2008).
5. Kiernan TJ, Flynn AM, Kearney P. Coronary embolism causing myocardial infarction in a patient with mechanical aortic valve prosthesis. Cardiovasc. Revasc. Med.112, 1416 (2006).

6. Nakazone MA, Tavares BG, Machado MN, Maia LN. Acute Myocardial Infarction due to Coronary Artery Embolism in a Patient with Mechanical Aortic Valve Prosthesis. Case. Rep. Med. 2010, 751857 (2010).

7. Ozturk C, Demirkol S, Demir M, et al. Mobile mass lesion in the aorta after transcatheter aortic valve implantation: Thrombus or residue calcification. Int. J. Cardiol. 198: $45-46$ (2015). 
8. Buturak A, Duygu E, Aksu E, Güngördük OA, Özgül S. Embolic acute myocardial infarction treated by intracoronary catheter aspiration embolectomy in a patient with mechanical aortic valve prosthesis. Anatol. J. Cardiol. 11, 461-462 (2011).

9. Ozturk C, Yildirim AO, Demir M, Balta S. Coronary Obstruction During Transcatheter Aortic Valve Replacement: Related to Calcification or Thrombus? Response. Rev. Esp. Cardiol. 69, 456-457 (2016).

10. Ozturk C, Celik T, Ozturk A, Balta S, Iyisoy A. Duration of antiplatelet or anticoagulant therapy after transcatheter aortic valve implantation in high risk patients; longer or shorter. Int. J. Cardiol. 210, 14-15 (2016).

11. Ozturk C, Celik T, Demirkol S, et al. The healing of spontaneous coronary artery dissection with conservative treatment: When to stop. Int. J. Cardiol. 189: 249-251 (2015).

12. Ozturk C, Yildirim AO, Demir M, et al. The spontaneous coronary artery dissection may need intervention in the proximal segment of the arteries. Int. J. Cardiol. 5273, 3052530528 (2015).
13. Iyisoy A, Kursaklioglu H, Kose S, et al. Acute myocardial infarction and left subclavian artery occlusion in Behçet's disease: a case report. Mt. Sinai. J. Med. 71, 330-334 (2004).

14. Iyisoy A, Kursaklioglu H, Kose $S$, et al. Spontaneous intimal dissection in a patient with post-infarct angina: identification with intravascular ultrasound and treatment with coronary stenting. Jpn. Heart. J. 44, 557-564 (2003).

15. Celik T, Balta S, Ozturk C, and Iyisoy A. Survival of the young patients with acute ST segment elevation myocardial infarction treated with primary percutaneous coronary intervention: Does gender matters? Int. J. Cardiol. 210, 54-55 (2016).

16. Celik T, Balta S, Ozturk C, Kaya MG, Aparci M. Predictors of No- Reflow Phenomenon in Young Patients With Acute ST-Segment Elevation Myocardial Infarction Undergoing Primary Percutaneous Coronary Intervention. Angiology pii: 0003319715605977 (2015). 